\title{
VIDEO TUTORIAL ENGLISH KUY UNTUK PEMBELAJARAN BAHASA INGGRIS PARIWISATA
}

\author{
Putu Dian Danayanti Degeng*, Irene Nany Kusumawardani, Galuh Nurul Indah Asri, Eleazar \\ Evan Moeljono \\ Fakultas IImu Budaya, Universitas Brawijaya
}

\section{Edcomtech}

\section{Jurnal Kajian Teknologi \\ Pendidikan}

Volume 6, No 2, Oktober 2021

236-242

DOI: 10.17977/um039v6i12021p236

Submitted 12-11-2019

Accepted 23-06-2021

\section{Corresponding Author*}

Putu Dian Danayanti Degeng

Universitas Brawijaya

Jl. Veteran, Ketawanggede, Kec.

Lowokwaru, Kota Malang, Jawa

Timur

Email: dian degeng@ub.ac.id

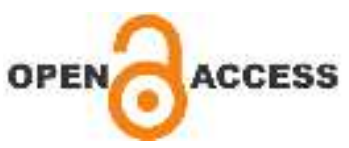

\begin{abstract}
Abstrak
Penelitian ini dilakukan untuk mengembangkan video tutorial sebagai media pembelajaran Bahasa Inggris yang layak di kampung tematik Kajoetangan Malang. "English Kuy" dikembangkan dengan menggunakan model pengembangan media instruksional dari Lee dan Owens. Berdasarkan hasil uji ahli, dapat disimpulkan bahwa video tutorial ini secara teoritis adalah baik dan dapat digunakan sebagai media pembelajaran Bahasa Inggris untuk level dasar/pemula. Video tutorial "English Kuy!" ini dapat digunakan oleh pekerja wisata di Malang terutama para penjual makanan, pemilik warung atau masyarakat umum yang tertarik untuk belajar Bahasa Inggris level dasar/pemula tentang pariwisata dan keramah-tamahan.

Kata kunci: Video Tutorial, ETP, Pekerja Wisata, Kampoeng Heritage Kayoetangan
\end{abstract}

\begin{abstract}
This research was conducted to develop video tutorial as a medium of English learning activity in the thematic village of Kajoetangan Malang. "English Kuy" was developed using an instructional media development model from Lee and Owens. Based on the results of experts validation, it can be concluded that this video tutorial is theoretically suitable and can be used as a medium of learning English for the basic/beginner level. The "English Kuy!" video tutorials can be used by tourism workers in Malang, especially food vendors, food stall owners or the general public who are interested in learning basic/beginner level English about tourism and hospitality.

Keywords: tutorial video, ETP, tourism worker, Kampoeng Heritage Kayoetangan
\end{abstract}

\section{LATAR BELAKANG}

Indonesia telah melakukan upaya yang luar biasa dalam mempromosikan pariwisata terlebih di kancah internasional. Salah satunya adalah dengan penetapan program tahun 2018 sebagai Visit Wonderful Indonesia Year oleh Kementerian Pariwisata Republik Indonesia. Negara ini diperkirakan akan menarik lebih dari 20 juta pengunjung asing pada 2019 dan memperoleh sekitar 17,6 miliar dolar AS dari kegiatan terkait pariwisata ("ekonomi"). Tidak hanya tentang peningkatan kunjungan wisatawan asing yang berdampak pada menguatnya devisa negara di tahun 2019, tapi juga kualitas Sumber daya manusia (SDM) yang merupakan komponen penting dalam 
mempromosikan industri pariwisata Indonesia perlu ditingkatkan. Dalam hal ini, penguasaan multibahasa, terutama bahasa Inggris sebagai bahasa Internasional akan memberikan kontribusi yang signifikan terhadap pengembangan keberlanjutan wisata budaya Negara (Prachanant, 2012) .

Berdasarkan hasil wawancara dengan Kepala Pemasaran Pariwisata di Dinas Kebudayaan dan Pariwisata (Disbudpar) Kota Malang, kemampuan komunikasi bahasa Inggris dari mereka yang bekerja di sektor pariwisata, misalnya; pengemudi, pemandu wisata, penduduk setempat, dan pelaku bisnis perhotelan di Malang pada umumnya dianggap lemah. Menurut Zahedpisheh et al. (2017), mereka yang bekerja di sektor pariwisata harus memiliki kemampuan Bahasa Inggris yang baik. Lemahnya kemampuan Bahasa Inggris para pekerja wisata dipengaruhi oleh beberapa hal, salah satunya adalah latar belakang pendidikan. Tidak semua pekerja wisata di Malang merupakan lulusan sekolah pariwisata; misalnya, para pekerja wisata di kampung-kampung tematik.

Kampung tematik merupakan salah satu program pemerintah Kota Malang untuk mengurangi kawasan kumuh (Akbar, 2018). Kebanyakan pekerja wisata di kampung-kampung ini adalah warga lokal yang tidak memiliki pengetahuan kepariwisataan. Hal ini tentu mempengaruhi kualitas layanan yang diberikan, baik kepada turis lokal maupun mancanegara. Kualitas layanan dapat dipengaruhi oleh penggunaan Bahasa sebagai alat komunikasi. Dalam industri pariwisata, Bahasa Inggris digunakan tidak hanya untuk komunikasi, melainkan juga untuk melakukan transaksi dan negosiasi antara turis dan pekerja wisata (Prachanant, 2012). English for Tourism and Hospitality (ETP) sebagai bagian dari English for Specific Purposes (ESP) merupakan Bahasa Inggris yang lebih banyak mendiskusikan mengenai penggunaan Bahasa Inggris untuk keperluan pariwisata dan keramah-tamahan (Cravotta, 1990). ETP meliputi percakapan, bahasa, kosakata, dan keperluan komunikasi untuk melayani wisatawan (Blue \& Harun, 2003).

Peningkatan kemampuan Bahasa Inggris para pekerja wisata (pembelajar) di kampung tematik kota Malang dapat dilakukan melalui beberapa cara, salah satunya adalah melalui penyediaan fasilitas belajar yang sesuai dengan karakteristik pembelajar. Fasilitas belajar yang sesuai dengan karakteristik pembelajar adalah dengan penggunaan media pembelajaran, khususnya video tutorial. Penggunaan video untuk pembelajaran Bahasa Inggris telah banyak digunakan. Menonton video sambil mempelajari Bahasa yang digunakan dapat meningkatkan penguasaan kosakata yang sering digunakan dalam pariwisata (Kacetl \& Frydrychova-Klimova, 2015).

Melalui kanal resmi YouTube Dinas Kebudayaan dan Pariwisata Kota Malang telah menyediakan beberapa video promosi Kota Malang dalam beberapa bahasa, termasuk bahasa Inggris. Namun, video yang memiliki isi pembelajaran bahasa Inggris pariwisata yang sesuai dengan karakteristik pekerja wisata di kampung tematik belum tersedia. Kondisi inilah yang melatarbelakangi pengembangan video pembelajaran bahasa Inggris untuk kegiatan pariwisata dengan isi aktual sekaligus memperkenalkan beberapa destinasi kuliner legendaris di kota Malang. Video ini dapat digunakan sebagai media pembelajaran untuk belajar Bahasa Inggris secara mandiri maupun dalam pelatihan bagi para pekerja wisata, khususnya mereka yang bergerak di bidang kuliner.

\section{METODE}

Penelitian ini menggunakan model pengembangan media instruksional yang 
dikemukakan oleh Lee \& Owens (2004) dengan menggunakan metode perolehan data kualitatif. Hal ini memudahkan peneliti untuk menghasilkan luaran yang tepat sesuai dengan kebutuhan sasaran penelitian. Dalam model tersebut, Lee dan Owens membagi proses penelitian ke dalam lima tahap: assessment/analysis, design, development, implementation, dan evaluation. Tahap pertama dibagi menjadi dua bagian yaitu analisis kebutuhan dan analisis front-end. Bagian ini dilaksanakan dalam bentuk observasi lapangan, wawancara, serta perizinan lokasi. Hasil analisi kebutuhan disajikan pada tabel 1.

Analisis front-end merupakan tahap pengambilan data secara detail terhadap kondisi lapangan. Proses ini dilaksanakan dalam bentuk wawancara oleh tim untuk menentukan kurikulum yang mendasari isi di dalam media pembelajaran.

Tabel 1. Lima Jenis Kebutuhan Pembelajaran di Kampung Heritage Kayoetangan (KHK)

\begin{tabular}{|c|c|}
\hline Jenis & Deskripsi \\
\hline Kebutuhan & Kemampuan berbahasa \\
\hline Normatif & $\begin{array}{l}\text { Inggris warga KHK masih } \\
\text { tergolong di bawah standar. }\end{array}$ \\
\hline $\begin{array}{l}\text { Kebutuhan } \\
\text { yang }\end{array}$ & $\begin{array}{l}\text { Pihak pengelola } \\
\text { mempercayai bahwa media }\end{array}$ \\
\hline Dirasakan & $\begin{array}{l}\text { inovatif untuk meningkatkan } \\
\text { minat dan kemampuan } \\
\text { berbahasa Inggris } \\
\text { dibutuhkan oleh warga KHK. }\end{array}$ \\
\hline $\begin{array}{l}\text { Kebutuhan } \\
\text { yang }\end{array}$ & $\begin{array}{l}\text { Kondisi KHK sebagai } \\
\text { kampung wisata menuntut }\end{array}$ \\
\hline Diminta & $\begin{array}{l}\text { warga kampung untuk } \\
\text { mampu berkomunikasi } \\
\text { dalam bahasa Inggris. }\end{array}$ \\
\hline Kebutuhan & Destinasi wisata \\
\hline Komparatif & $\begin{array}{l}\text { internasional di Indonesia } \\
\text { sudah menggunakan bahasa } \\
\text { Inggris sebagai bahasa } \\
\text { pengantar sehari-hari. }\end{array}$ \\
\hline Kebutuhan & Disbudpar Kota Malang \\
\hline Antisipatif & $\begin{array}{l}\text { menargetkan adanya } \\
\text { peningkatan jumlah turis } \\
\text { asing di Malang. }\end{array}$ \\
\hline
\end{tabular}

Tabel 2. Konversi tingkat pencapaian skala 1-5

\begin{tabular}{|c|c|c|}
\hline $\begin{array}{c}\text { Tingkat } \\
\text { Pencapaian } \\
(\%)\end{array}$ & Kualifikasi & Keterangan \\
\hline (5) $90-100$ & Sangat baik & $\begin{array}{l}\text { Tidak perlu } \\
\text { direvisi }\end{array}$ \\
\hline (4) 75-89 & Baik & Sedikit revisi \\
\hline (3) $65-74$ & Cukup & $\begin{array}{l}\text { Revisi } \\
\text { secukupnya }\end{array}$ \\
\hline (2) 55-64 & Kurang & $\begin{array}{l}\text { Banyak yang } \\
\text { perlu } \\
\text { direvisi }\end{array}$ \\
\hline (1) 0-54 & $\begin{array}{l}\text { Sangat } \\
\text { kurang }\end{array}$ & $\begin{array}{l}\text { Mengulang } \\
\text { pembuatan } \\
\text { produk }\end{array}$ \\
\hline
\end{tabular}

Kedua analisis tersebut menghasilkan sebuah kesimpulan bahwa kebutuhan media pembelajaran bahasa Inggris diperlukan untuk menunjang keberlanjutan pengembangan sektor pariwisata di Kota Malang, khususnya di KHK. Tahap selanjutnya adalah design dan development. Media pembelajaran yang dikembangkan berbentuk video tutorial. Video menyajikan audio visual untuk menumbuhkan minat dan motivasi belajar terhadap materi pembelajaran serta memahami materi yang diajarkan dengan lebih baik daripada buku. Video tersebut kemudian divalidasi oleh tim ahli untuk diverifikasi sebelum diujicobakan pada pengguna dengan menggunakan pedoman pada tabel 2 .

HASIL

Pengembangan video tutorial Bahasa Inggris "English Kuy!" adalah rangkaian video pembelajaran Bahasa Inggris yang diperuntukkan bagi pelaku usaha kuliner dan pariwisata di kota Malang. Pariwisata kuliner merupakan destinasi wisata yang semakin penting belakangan ini. Judul video tutorial ini diambil dari Bahasa Malangan yang artinya 'mari kita gunakan bahasa Inggris'. Seri video dibuat menjadi tiga episode dengan masing-masing durasi 15-20 menit yang 
mencakup beberapa topik; Greeting and Hospitality, Food Vocabulary, dan Malang Local Food. Video tutorial ini dimaksudkan untuk pebelajar tingkat pemula, lebih tepatnya untuk penjual makanan jalanan di Malang yang jarang berbicara bahasa Inggris sebelumnya.

Merujuk pada latar belakang pembelajar yang juga merupakan sasaran dari pengembangan video tutorial ini, maka penggunaan bahasa asli (bahasa daerah dan bahasa Indonesia) masih digunakan. Selaras dengan pendapat Vazokiray (2015) dan Udoyono (2013) bahwa percakapan yang efektif digunakan sebagai model belajar bahasa Inggris pelaku wisata lokal adalah percakapan yang dilengkapi dengan terjemahan berbahasa Indonesia, serta telah dimodifikasi dan dikembangkan sesuai dengan kondisi wisata. Kendati demikian, video ini tidak hanya menunjukkan cara memulai percakapan dan menawarkan produk kepada orang asing, tetapi juga bagaimana melakukan transaksi dalam bahasa Inggris. Materi yang disediakan dalam bentuk frasa dan kosakata umum, menggunakan realita kehidupan pelaku usaha pariwisata dan kuliner yang berada di sekeliling Alun-Alun kota Malang. Dalam penyampaian materinya, "English Kuy!" Episode 1 hingga 3 menggunakan metode show and tell yang mengutamakan kemampuan komunikasi sederhana yang dikembangkan dari proses seseorang yang senang untuk menunjukkan sesuatu seperti makanan; rasa dan bahan dapur dan jumlah uang di sekitarnya (Dananjaya, 2010).

Pada realitanya, para pelaku wisata dituntut untuk dapat mengikuti perkembangan zaman yang dinamis sehingga melek huruf merupakan salah satu poin penting dari parameter pariwisata yang mensejahterakan rakyat (Damanik, 2013). Dengan peran serta bahasa Inggris yang optimal, Sindik \& Božinović (2013) percaya bahwa pelaku wisata mampu menaikkan daya pelayanan pada pengunjung wisata. Oleh karena itu "English Kuy!" dirancang untuk memberikan pemahaman percakapan dan kosakata bahasa Inggris yang baik dengan memberikan ilustrasi gambar, video, dan juga terjemahan berbahasa Indonesia (Morris, 2017).

\section{Hasil Validasi Ahli Media}

Produk pengembangan video tutorial Bahasa Inggris "English Kuy" telah divalidasi oleh ahli media berdasarkan angket uji ahli media. Aspek-aspek penilaian ahli media antara lain aspek suara, musik, narasi dan penyajian video. Pada episode 1 mengenai "Greeting and Hospitality", hasil validasi ahli media menyatakan bahwa dalam aspek suara dan juga musik, masih diperlukan adanya peningkatan kualitas suara aktor dan menambahkan sumber referensi untuk musik, meski penggunaan musik sesuai dengan isi dan istilah bahasa Inggris terbilang umum, instruksional, dan sangat komunikatif. Ahli media juga menyatakan bahwa English Kuy! episode 1 memiliki narasi yang bagus dan sangat cocok dengan tujuan pembelajaran, materi, intonasi, dan skrip. Berdasarkan hasil tersebut, tingkat pencapaian yang didapat untuk produk ini adalah $86,6 \%$ dengan kualifikasi baik.

Untuk analisis media pada episode 2 tentang "Food Vocabulary" dalam aspek fisik dan narasi memiliki penilaian yang sama bagusnya. Namun dalam hal suara, ahli media mengatakan bahwa suara aktor pada episode ini masih sangat perlu untuk diperbaiki meski memiliki artikulasi yang cukup. Sedangkan pada penilaian aspek musik, ahli media memberikan komentar 
yang sama bahwa masih perlu adanya penambahan informasi tentang sumber musik. Untuk presentasi video dari episode 2 ini, memiliki voice over sangat bagus dan format bagus, dengan durasi video kurang dari 20 menit. Berdasarkan hasil tersebut, tingkat pencapaian yang didapat untuk produk ini adalah 84,4\% dengan kualifikasi baik.

Sedangkan di episode 3 mengenai "Malang Local Food" yang dibagi menjadi 2 bagian dengan durasi total 32.12 menit ini menceritakan tentang kelezatan makanan lokal Malang yang tersebar di sekitar Alun-Alun Kota Malang. Dengan menampilkan berbagai macam makananhingga minuman yang legendaris dan terkenal, informasi penilaian ahli media dalam aspek fisik, narasi, dan presentasi video di episode 3 ini sama baiknya dengan episode 1 dan 2. Namun, kendala volume suara aktor dan minimnya informasi mengenai musik, masih sangat perlu diperbaiki. Berdasarkan hasil tersebut, tingkat pencapaian yang didapat untuk produk ini adalah $86,6 \%$ dengan kualifikasi baik.

\section{Hasil Validasi Ahli Isi}

Produk pengembangan video tutorial Bahasa Inggris "English Kuy!" telah divalidasi oleh ahli isi berdasarkan angket uji ahli isi. Aspek-aspek penilaian ahli isi antara lain kesesuaian materi dengan tujuan pembelajaran, keruntutan penyampaian materi, ketepatan pemilihan materi, relevansi materi dengan kebutuhan pebelajar. Ahli isi menyatakan bahwa isi video "English Kuy!" episode 1: "Greeting and Hospitality" sesuai dengan tujuan pembelajaran, pengiriman materi baik, presentasi materi sangat baik, proporsi materi baik, relevansi materi sangat relevan, dan informasi yang cukup tentang referensi/ sumber materi. Secara umum, tingkat pencapaian yang didapat untuk produk ini adalah $83,3 \%$ dengan kualifikasi baik. Artinya secara teoritis, isi video ini cocok digunakan untuk belajar Bahasa Inggris Greeting and Hospitality untuk tingkat pemula. Pada episode 2 "Food Vocabulary", ahli isi mengatakan bahwa isi video sesuai dengan tujuan pembelajaran, pengiriman materi baik, presentasi materi sangat baik, proporsi materi baik, relevansi materi sangat relevan, dan informasi yang cukup tentang referensi/sumber materi. Secara umum, tingkat pencapaian yang didapat untuk produk ini adalah 83,3\% dengan kualifikasi baik. Artinya secara teoritis, isi video ini cocok digunakan untuk belajar Kosakata Makanan Bahasa Inggris untuk tingkat pemula.

Penilaian ahli isi untuk episode 3 "Malang Local Food" menyatakan bahwa isi video sesuai dengan tujuan pembelajaran, pengiriman materi baik, presentasi materi sangat baik, proporsi materi baik, relevansi materi sangat relevan, dan informasi yang cukup tentang referensi/sumber materi. Secara umum, tingkat pencapaian yang didapat untuk produk ini adalah 83,3\% dengan kualifikasi baik. Artinya secara teoritis, isi video ini cocok digunakan untuk mempelajari "Makanan Lokal Malang" untuk tingkat pemula.

\section{PEMBAHASAN}

Media pembelajaran merupakan bagian dari sumber belajar dan sekaligus bagian integral teknologi pendidikan yang perlu dimanfaatkan dan didayagunakan untuk menunjang efektivitas proses pembelajaran ((Jatmiko et al., 2017). Pengembangan video tutorial "English Kuy!" dengan mengangkat tema sehari-hari serta gaya bahasa yang mudah dan praktis merupakan upaya pendekatan pembelajaran bahasa asing dengan nilainilai lokal. Pemilihan tema ini dapat meningkatkan keinginan pembelajar, khususnya para pekerja wisata untuk 
berkomunikasi dengan lebih percaya diri (Zarrinabadi \& Alipour, 2020).

Pemanfaatan dan pendayagunaan berbagai jenis sumber belajar tidak harus mahal, mutakhir, dan canggih, tetapi dapat juga memanfaatkan sumbersumber belajar yang tersedia di lingkungan sekitar tergantung tujuan, karakteristik pembelajar, termasuk pendekatan yang digunakan (Abidin, 2017). Selain itu pebelajar kadangkala merasa kesulitan pada saat mengilustrasikan isi pembelajaran berupa pengetahuan konsep (Soepriyanto \& Rahmatullah, 2017), dengan demikian penggunaan video diharapkan dapat memberikan ilustrasi yang langsung dan nyata. Pengambilan setting video di sekitar rumah warga dan tujuan wisata lokal diharapkan dapat memberi gambaran penerapan teori bahasa asing dalam kebutuhan warga pelaku wisata di Malang. Secara formal pendidikan diselenggarakan oleh institusi pendidikan. Namun wujud nyata peran dan tanggung jawab pendidikan oleh keluarga, lembaga pendidikan dan masyarakat tetap tidak dapat dipisahkan (Kuswandi, 2017). Oleh karena itu, pelibatan unsur-unsur penting keluarga dan masyarakat diharapkan mampu memberikan sentuhan yang lebih bermakna dan berkualitas atas dasar kebutuhan yang dirasakan oleh sekolah dan masyarakat itu sendiri.

Teknologi informasi beberapa tahun belakangan ini mengalami perkembangan yang sangat cepat. Perkembangan tersebut telah mengubah paradigma masyarakat dalam mencari dan mendapatkan informasi serta pengetahuan. Pemilihan kanal YouTube sebagai media diseminasi menjadi suatu upaya yang sejalan dengan pemanfaatan teknologi dalam pembelajaran di era digital. Penggunaan YouTube dalam pembelajaran bahasa memberikan banyak keuntungan, salah satunya adalah, akses video pembelajaran secara online yang dapat membuka kesempatan kepada pembelajar untuk mendapatkan pengetahuan dengan lebih mudah (Ho \& Tai, 2020; Maziriri et al., 2020).

\section{SIMPULAN}

Pengembangan Video Tutorial Bahasa Inggris untuk Pariwisata di Malang Jawa Timur, Indonesia yang berjudul English Kuy! terdiri atas tiga episode antara lain; episode 1: Greeting and Hospitality, episode 2: Food Vocabulary, dan episode 3: Malang Local Food; telah divalidasi oleh para ahli media dan isi. Berdasarkan temuan tersebut, kedua ahli sepakat bahwa produk secara teoritik baik dan dapat digunakan sebagai media untuk belajar bahasa Inggris untuk tingkat pemula sekalipun masih banyak aspek yang bisa ditingkatkan lagi untuk pengembangan ke depannya. English Kuy! dapat digunakan sebagai media pembelajaran oleh pekerja pariwisata terutama para pelopor yang tertarik untuk belajar bahasa Inggris tentang Pariwisata dan kuliner. Agar lebih mudah diakses, video tutorial bahasa Inggris English Kuy! episode 1, 2, dan 3 telah diunggah di laman YouTube dan dapat diunduh secara bebas.

\section{UCAPAN TERIMAKASIH}

Pengembangan video 'English Kuy!' ini merupakan hasil dari proyek penelitian serta pengabdian masyarakat DPP SPP 2019 yang didanai oleh Fakultas IImu Budaya Universitas Brawijaya.

\section{REFERENSI}

Abidin, Z. (2017). Penerapan pemilihan media pembelajaran. Edcomtech Jurnal Kajian Teknologi Pendidikan, 1(1), 9-20.

Akbar, T. (2018). Kampung tematik sebagai bentuk partisipasi masyarakat dalam permasalahan permukiman kumuh di Kota Malang. Wahana: Tridarma Perguruan Tinggi, 70(2), 37-48. 
Blue, G. M., \& Harun, M. (2003). Hospitality Language as a Professional Skill. English for Specific Purposes Pergamon Journal. 22(1), 73-91.

https://doi.org/https://doi.org/10.1 016/S0889-4906(01)00031-X

Damanik, J. (2013). Pariwisata Indonesia; antara peluang dan tantangan.

Dananjaya, U. (2010). Media pembelajaran aktif. Nuansa cendekia.

Ho, W. Y. J., \& Tai, K. W. H. (2020). Doing expertise multilingually and multimodally in online English teaching videos. System, 94, 102340. https://doi.org/https://doi.org/10.1 016/j.system.2020.102340

Jatmiko, P. D., Wijayantin, A., \& Susilaningsih, S. (2017). Pengaruh pemanfaatan video pembelajaran terhadap hasil belajar IPA kelas IV sekolah dasar. Edcomtech Jurnal Kajian Teknologi Pendidikan, 1(2), 153-156.

Kacetl, J., \& Frydrychova-Klimova, B. (2015). English vocabulary in video clips on travel and tourism. ProcediaSocial and Behavioral Sciences, 182, 364-368.

https://doi.org/https://doi.org/10.1 016/j.sbspro.2015.04.788

Kuswandi, D. (2017). Model Pembelajaran IPS yang Menggunakan Unsur-Unsur Penting Kehidupan Nyata Masyarakat Sebagai Sumber Belajar. Edcomtech Jurnal Kajian Teknologi Pendidikan, 1(1), 49-58.

Lee, W. W., \& Owens, D. L. (2004). Multimedia-based instructional design: computer-based training, web-based training, distance broadcast training, performancebased solutions. John Wiley \& Sons.

Maziriri, E. T., Gapa, P., \& Chuchu, T. (2020). Student Perceptions towards the Use of YouTube as an Educational Tool for Learning and Tutorials. International Journal of Instruction, 13(2), 119-138.

Morris, C. E. (2017). Flash on English for Tourism Second Edition ESP Series.

Prachanant, N. (2012). Needs analysis on English language use in tourism industry. Procedia-Social and Behavioral Sciences, 66, 117-125. https://doi.org/https://doi.org/10.101 6/j.sbspro.2012.11.253

Sindik, J., \& Božinović, N. (2013). Importance of foreign languages for a career in tourism as perceived by students in different years of study. Tranzicija, 15(31.), 16-28.

Soepriyanto, Y., \& Rahmatullah, B. (2017). Pengembangan Video Termediasikan Augmented Reality sebagai Electronic Performance Support System dalam Pembelajaran. Edcomtech Jurnal Kajian Teknologi Pendidikan, 1(2), 111-117.

Udoyono, B. (2013). Conducting Java-bali Overland Tours In English \& French.

Vazokiray, R. (2015). English for Tour Guides. Pustaka Pelajar.

Zahedpisheh, N., Bakar, A., Zulqarnain, B., \& Saffari, N. (2017). English for Tourism and Hospitality Purposes (ETP). English Language Teaching, 10(9), 86-94.

Zarrinabadi, N., \& Alipour, F. (2020). Sequencing inquiry tasks and video modeling examples to enhance $\mathrm{L} 2$ willingness to communicate. Learning and Motivation, 72, 101669. https://doi.org/https://doi.org/10.101 6/j.Imot.2020.101669 